\title{
Physical Activity Levels, Exercise Preferences, and Exercise Barriers in Children and Adolescents after Cancer Treatment
}

\author{
Ji Young Kim \\ Yonsei University \\ Samuel Yoo \\ Yonsei University \\ Su Jin Yeon \\ Yonsei University \\ Ji Hee Min \\ Yonsei University \\ Dong-il Kim \\ Incheon National University \\ Ji Won Lee \\ Yonsei University College of Medicine \\ Jung Woo Han \\ Yonsei University College of Medicine \\ Chuhl Joo Lyu \\ Yonsei University College of Medicine \\ Justin Jeon ( $\nabla_{\text {jjeon@yonsei.ac.kr) }}$ \\ Yonsei University https://orcid.org/0000-0001-7978-4271
}

\section{Research Article}

Keywords: Childhood cancer, adolescent survivor, physical activity preference, exercise barrier

Posted Date: June 16th, 2021

DOl: https://doi.org/10.21203/rs.3.rs-520789/v1

License: (c) (i) This work is licensed under a Creative Commons Attribution 4.0 International License.

Read Full License 


\section{Abstract}

Purpose: The purpose of the current study was to explore physical activity (PA) and exercise participation, exercise preferences, and barriers to PA in childhood cancer survivors.

Methods: We surveyed 120 childhood cancer survivors in childhood and adolescence from the pediatric oncology center in South Korea between March and August 2017. The modified Exercise \& Quality of Life questionnaire, Korea Youth Risk Behavior Web-based Survey, and Godin Leisure-Time Questionnaire were used to assess PA levels, preferences, and exercise barriers.

Results: Among 120 participants (72 boys, 48 girls) whose average age at the time of the survey was $14.57 \pm 3$ years and average age at diagnosis was 8.22 years, only $6.9 \%$ of male participants and $2.1 \%$ of female participants met the PA recommendations for children (at least $60 \mathrm{~min}$ of moderate PA per day). The most preferred sporting activities included soccer, basketball, strengthening exercises, badminton, dance, and taekwondo. They generally had positive attitudes toward exercise, and more than $63 \%$ of participants intended to exercise the following month. The four most prevalent perceived barriers to exercise were lack of time, poor health, reluctance to sweat, and lack of exercise skills.

Conclusions: While most childhood cancer survivors did not meet the PA recommendation, most of them agreed that exercise was beneficial, and they intended to participate in exercise. Exercise and PA programs should be tailored to the personal health and preferences of childhood cancer survivors to increase PA and exercise participation in this group.

\section{Introduction}

Cancer treatments have greatly improved the average life expectancy of childhood cancer survivors [1], shifting the focus of childhood cancer treatment from saving lives to preserving long-term health and quality of life. In particular, physical and psychological problems resulting from cancer and its treatment are currently important issues in childhood cancer survivors. Oeffinger et al. reported that $62.3 \%$ of 10,387 survivors had at least one chronic health condition, of which $27.5 \%$ were considered to have severe and/or life-threatening conditions, such as major joint replacement, congestive heart failure, second malignant neoplasms, and coronary artery disease [2].

Recently, two important studies showed the positive impact of exercise and physical activity (PA) in improving the prognosis of childhood cancer survivors. Scott et al. examined the association between exercise participation and mortality in 15,450 adult survivors of childhood cancer. They reported that increased exercise participation and maintenance of high levels of exercise participation were associated with $40 \%$ and $44 \%$ reduction in all-cause mortality, respectively, compared with childhood cancer survivors who had consistently low levels of exercise participation [3]. Ness et al. reported that decreased cardiopulmonary fitness was prevalent among childhood cancer survivors and was associated with increased all-cause mortality, demonstrating the importance of exercise and PA in improving the prognosis among childhood cancer survivors [4]. In addition to these two recent studies, previous studies 
have suggested that PA may mitigate or prevent obesity, diabetes, cardiovascular disease, or low functional capacity in childhood cancer survivors $[2,5,6]$. Gotte et al. suggested that most PAs have a positive impact on the secondary prevention of chronic fatigue and cardiorespiratory disease [7]. PA may also reduce the severity of late effects and improve the quality of life (QOL) [8].

Although childhood cancer survivors may benefit from PA and exercise participation, such participation during and after treatment may be challenging [9-11]. However, studies that only included childhood cancer survivors who were pre-adolescent/adolescents showed that they generally had lower levels of PA and exercise participation [12-14]. In this regard, studies by Keats et al. showed interesting results: they analyzed the PA levels of adolescent cancer survivors before cancer diagnosis, during treatment, and after treatment. They reported that $47.1 \%$ of adolescent cancer survivors were temporary relapsers, whose PA levels decreased during treatment, but recovered after completion of cancer treatment. Surprisingly, $23 \%$ of adolescent cancer survivors maintained good PA levels before, during, and after cancer treatment $[13,14]$.

More recently, Antwi et al. performed a pooled analysis of 8 observational studies examining PA and physical fitness in childhood cancer survivors compared with non-cancer controls and demonstrated significantly lower levels of PA in the cancer group than in the controls [15]. Although this meta-analysis showed significantly lower PA levels in childhood cancer survivors, time since treatment, geographical location, and the culture in which studies were conducted may have influenced the level of PA participation. Previous studies from Europe and North America showed relatively high levels of PA participation among childhood cancer survivors: $30-50 \%$ of childhood cancer survivors met the PA guidelines [16-18]. Conversely, only 13.7-26.3\% of adolescents without cancer from eight different Asian cities met the PA guidelines. It would thus be expected that a relatively smaller proportion of childhood cancer survivors from Asian countries would meet the PA guidelines. This was confirmed in studies from Asian regions [19], which clearly revealed the need to increase the levels of PA among Asian childhood cancer survivors.

Developing effective strategies to increase PA and exercise participation in childhood cancer survivors is necessary. In order to develop effective programs, understanding the PA participation levels, exercise preferences, attitudes toward exercise, and exercise barriers in childhood cancer survivors is important. However, few studies have explored these parameters among Asians. Furthermore, there are few studies on childhood cancer survivors who were pre-adolescents and adolescents. Therefore, the purpose of the current study was to explore exercise participation patterns, exercise preferences, and perceived barriers in childhood cancer survivors in childhood and adolescence.

\section{Methods}

\section{Study design and participants}


This was a cross-sectional study that surveyed 120 childhood cancer survivors recruited from Yonsei Cancer Hospital between March and August 2017. Childhood cancer survivors aged 8-18 years who had undergone standard surgery and chemotherapy at least 1 month prior were considered eligible. Patients with severe cognitive or mental disorders were excluded from the study. All participants and their parents signed a consent form before participating in the study. The study was approved by the Institutional Review Board of the Yonsei University College of Medicine (approval no. 4-2017-0065).

\section{Measurements}

Personal information, including patient demographics, type of cancer, treatment, and medical history, was collected.

\section{Exercise preferences, exercise attitudes, and intentions to exercise}

Exercise preferences, exercise attitudes, and intentions to exercise were assessed using a customized questionnaire [20]. The questionnaire had three domains that identified exercise preferences (seven items), beliefs (six items), and intention (two items).

\section{PA levels and exercise barriers}

The Godin Leisure-Time Questionnaire (GLTEQ) and Korea Youth Risk Behavior Web-based Survey (KYRBWS) questionnaire were used to assess PA levels and exercise barriers. The GLTEQ provides information on the frequency and duration of strenuous, moderate, and mild leisure PA per week [21]. The KYRBWS questionnaire, designed and tested by the Korea Centers for Disease and Prevention, includes participation in physical education (PE) classes, participation in sports clubs in schools, and exercise barriers [22].

\section{Statistical analysis}

All calculations were performed using the Statistical Package for Predictive Analytics Software (PASW)/SPSS (version 23.0; SPSS Inc., Chicago, IL, USA). Data are presented as mean \pm standard deviation. Descriptive analyses were used to evaluate demographic information, PA levels, participation in PE classes, sedentary time, exercise preferences, exercise attitudes, intention to exercise, and exercise barriers. The chi-square test was used to assess group differences in the categorical variables. The normality of distribution was verified using the Shapiro-Wilk test. The Mann-Whitney test was used to examine non-normally distributed variables. Statistical significance was set at $P<.05$.

\section{Results}

\section{Participant characteristics}


Among the 120 childhood cancer survivors included in the current study, 72 were boys (60\%), and the mean age of the participants was $14.57 \pm 3.00$ years. The mean age at diagnosis was $8.22 \pm 5.35$ years. The detailed characteristics of the participants are summarized in Table 1. 
Table 1

Demographic information $(\mathrm{N}=120)$

\begin{tabular}{|c|c|c|c|}
\hline Sex, male, n (\%) & \multicolumn{3}{|l|}{$72(60)$} \\
\hline Age at study (years) & \multicolumn{3}{|l|}{$14.57 \pm 3.00$} \\
\hline \multirow[t]{5}{*}{ Education status, n (\%) } & Attending school & \multicolumn{2}{|c|}{$97(80.8)$} \\
\hline & On leave of absence & \multicolumn{2}{|c|}{$7(5.8)$} \\
\hline & Ready for qualification examination & \multicolumn{2}{|c|}{$2(1.7)$} \\
\hline & Other ${ }^{\mathrm{a}}$ & \multicolumn{2}{|c|}{$13(10.8)$} \\
\hline & No response & \multicolumn{2}{|c|}{$1(0.8)$} \\
\hline Days of absence & \multirow{2}{*}{\multicolumn{3}{|c|}{$0.42 \pm 1.12$}} \\
\hline ( $\mathrm{n}=97$, attending school) & & & \\
\hline \multirow[t]{4}{*}{ Grades } & High & \multicolumn{2}{|c|}{$28(23.3)$} \\
\hline & Middle & \multicolumn{2}{|c|}{$74(61.7)$} \\
\hline & Low & \multicolumn{2}{|c|}{$17(14.2)$} \\
\hline & No response & \multicolumn{2}{|c|}{$1(0.8)$} \\
\hline \multirow[t]{7}{*}{ Diseases, n (\%) } & Leukemia & \multicolumn{2}{|c|}{$52(43.3)$} \\
\hline & Brain tumor & \multicolumn{2}{|c|}{$16(13.3)$} \\
\hline & Lymphoma & \multicolumn{2}{|c|}{$13(10.8)$} \\
\hline & Bone tumor & \multicolumn{2}{|c|}{$9(7.5)$} \\
\hline & Neuroblastoma & \multicolumn{2}{|c|}{$8(6.7)$} \\
\hline & Wilms' tumor & \multicolumn{2}{|c|}{$5(4.2)$} \\
\hline & Other ${ }^{b}$ & \multicolumn{2}{|c|}{$17(14.2)$} \\
\hline Age at diagnosis (years) & $8.22 \pm 5.35$ & & \\
\hline \multirow[t]{3}{*}{ Therapy, n (\%) } & Chemotherapy & Yes & $112(93.3)$ \\
\hline & Radiation & Yes & $35(29.2)$ \\
\hline & Surgery & Yes & $38(31.7)$ \\
\hline
\end{tabular}

a Online education, home schooling, or none

${ }^{b}$ Rhabdomyosarcoma, hepatoma, retinoblastoma, pancreatic cancer, or Langerhans cell histiocytosis

${ }^{\mathrm{C}}$ Liver transplantation 


\begin{tabular}{|c|c|c|c|}
\hline \multirow[t]{3}{*}{ Sex, male, $n(\%)$} & \multicolumn{3}{|l|}{$72(60)$} \\
\hline & Stem cell transplantation & Yes & $26(21.7)$ \\
\hline & Other ${ }^{\mathrm{C}}$ & Yes & $4(3.3)$ \\
\hline Recurrence & Yes & $6(5$ & \\
\hline \multirow[t]{6}{*}{ Income for a month (won) } & No income & $3(2$ & \\
\hline & $<1,000,000$ & $4(3$ & \\
\hline & $1,010,000-3,000,000$ & 32 & \\
\hline & $3,010,000-5,000,000$ & 51 & \\
\hline & $>5,010,000-$ & 29 & \\
\hline & No response & $1(3$ & \\
\hline \multicolumn{4}{|c|}{ a Online education, home schooling, or none } \\
\hline \multicolumn{4}{|c|}{ b Rhabdomyosarcoma, hepatoma, retinoblastoma, pancreatic cancer, or Langerhans cell histiocytos } \\
\hline${ }^{\mathrm{c}}$ Liver transplantation & & & \\
\hline
\end{tabular}

\section{PA levels, participation in PE classes, and participation in sports clubs in schools}

The duration of participation in leisure-time vigorous, moderate, and mild PA was $40.33 \pm 122.03,80.21 \pm$ 142.05 , and $58.92 \pm 112.67 \mathrm{~min} /$ week, respectively (Table 2). Male participants engaged more in vigorous PA for leisure than female participants (vigorous PA: $59.86 \pm 149.66$ vs. $11.04 \pm 49.04 \mathrm{~min} /$ week, $P$ $=.012$ ). 
Table 2

Physical activity levels of childhood cancer survivors

\begin{tabular}{|c|c|c|c|c|c|}
\hline All participants & $\mathrm{n}(\%)$ & $\begin{array}{l}\text { Total } \\
(\mathrm{N}=120)\end{array}$ & $\begin{array}{l}\text { Male } \\
(n=72)\end{array}$ & $\begin{array}{l}\text { Female }(n \\
=48)\end{array}$ & $\begin{array}{l}P \\
\text { value }\end{array}$ \\
\hline \multirow{7}{*}{$\begin{array}{l}\text { PA for leisure time } \\
\text { (min) }\end{array}$} & $\begin{array}{l}\text { Vigorous \& } \\
\text { moderate PA }\end{array}$ & $\begin{array}{l}120.54 \pm \\
192.25\end{array}$ & $\begin{array}{l}161.18 \pm \\
227.02\end{array}$ & $\begin{array}{l}59.58 \pm \\
96.93\end{array}$ & .016 \\
\hline & \multirow[t]{2}{*}{ Vigorous PA } & \multirow{2}{*}{$\begin{array}{l}40.33 \pm \\
122.03\end{array}$} & $59.86 \pm$ & $11.04 \pm$ & \multirow[t]{2}{*}{.012} \\
\hline & & & 149.66 & 49.04 & \\
\hline & \multirow[t]{2}{*}{ Moderate PA } & \multirow{2}{*}{$\begin{array}{l}80.21 \pm \\
142.05\end{array}$} & $101.32 \pm$ & $48.54 \pm$ & \multirow[t]{2}{*}{.134} \\
\hline & & & 166.56 & 86.44 & \\
\hline & \multirow[t]{2}{*}{ Mild PA } & \multirow{2}{*}{$\begin{array}{l}58.92 \pm \\
112.67\end{array}$} & $57.22 \pm$ & $61.46 \pm$ & \multirow[t]{2}{*}{.714} \\
\hline & & & 115.18 & 109.95 & \\
\hline $\begin{array}{l}\text { Participants attending } \\
\text { school }\end{array}$ & $\mathrm{n}(\%)$ & $\begin{array}{l}\text { Total }(n= \\
97)\end{array}$ & $\begin{array}{l}\text { Male }(n= \\
59)\end{array}$ & $\begin{array}{l}\text { Female }(\mathrm{n} \\
=38)\end{array}$ & $\begin{array}{l}P \text { - } \\
\text { value }\end{array}$ \\
\hline \multirow{4}{*}{$\begin{array}{l}\text { Participation in PE } \\
\text { class }\end{array}$} & None & $16(16.5)$ & $6(10.2)$ & $10(26.3)$ & \multirow[t]{4}{*}{.015} \\
\hline & 1 time/wk & $12(12.4)$ & $4(6.8)$ & $8(21.1)$ & \\
\hline & 2 times/wk & $39(40.2)$ & $28(47.5)$ & $11(28.9)$ & \\
\hline & > 3 times/wk & $30(30.9)$ & $21(35.6)$ & $9(23.7)$ & \\
\hline \multirow{5}{*}{$\begin{array}{l}\text { Sport club } \\
\text { participation }\end{array}$} & None & $62(63.9)$ & $34(57.6)$ & 28 (73.7) & \multirow[t]{5}{*}{.388} \\
\hline & 1 team & $28(28.9)$ & 19 (32.2) & $9(23.7)$ & \\
\hline & 2 teams & $3(3.1)$ & $3(5.1)$ & $0(0)$ & \\
\hline & 3 teams & $3(3.1)$ & $2(3.4)$ & $1(2.6)$ & \\
\hline & $>4$ teams & $1(1.0)$ & $1(1.7)$ & $0(0)$ & \\
\hline
\end{tabular}

Among the 120 participants, $97(80.8 \%)$ attended school. Sixteen (16.5\%) participants had not attended a PE class; 12 (12.4\%) participants attended a PE class once a week, 39 (40.2\%) twice a week, and 30 $(30.9 \%)$ more than three times per week. Participation in PE classes and sports clubs in school was significantly different between male and female participants $(P=.015)$. Sixty-two participants $(63.9 \%)$ did not participate in any sports clubs, while $28(28.9 \%)$, three $(3.1 \%)$, three $(3.1 \%)$, and one $(1.0 \%)$ participated in one, two, three, and four sports clubs, respectively.

\section{Exercise preferences, exercise attitudes, intentions to exercise, and exercise barriers}


Table 3 shows exercise preferences, exercise attitudes, and intentions to exercise. Among the participants, $78(65.0 \%)$ responded that they would like to receive exercise-related information and $62(51.7 \%)$ responded that they wanted to participate in an exercise program. 
Table 3

Exercise preferences among childhood cancer survivors

\section{Exercise preferences}

$\mathrm{n}(\%)$

Do you want to receive information about an exercise program for childhood cancer survivors?

Yes

No

Do you want to participate in an exercise program?

Yes

No

What type of exercise would you be most interested in? (Write up to 3

Soccer

preferred exercises.)

$\begin{array}{ll}\text { Basketball } & 28 \\ \begin{array}{l}\text { Resistance } \\ \text { exercise }\end{array} & 27\end{array}$

Badminton

23

Dance

20

Taekwond

12

\begin{tabular}{l} 
Dodgeball \\
Jumping rope \\
\hline Swimming \\
\hline
\end{tabular}

Table tennis

6

Other $^{\mathrm{a}}$

Who would you prefer to exercise with?

Family

Friends

a Baseball, volleyball, tennis, aerobic, boxing, golf, Pilates, billiards, waking, cycling, jogging, jiu-jitsu, aquarobics, balling, or skating

b Alone

c School, schoolyard, or indoors

dOccasionally or daily 
Other cancer

survivors

General public

Exercise 8

specialist

Other ${ }^{b}$

No response

Where would you prefer for an exercise program to take place?

House

22

Gym

Hospital

No preference

Other ${ }^{\mathrm{c}}$

No response

How long do you think you would be able to exercise? (min)

\begin{tabular}{ll} 
None & $0(0)$ \\
\hline $1-10$ & 3 \\
& $(2.5)$ \\
$10-20$ & 15 \\
& $(12.5)$ \\
$20-30$ & 33 \\
& $(27.5)$ \\
\hline
\end{tabular}

a Baseball, volleyball, tennis, aerobic, boxing, golf, Pilates, billiards, waking, cycling, jogging, jiu-jitsu, aquarobics, balling, or skating

${ }^{\mathrm{b}}$ Alone

c School, schoolyard, or indoors

dOccasionally or daily 


$$
>30
$$

No response

How often would you prefer to attend? (times/wk)

\begin{tabular}{ll}
5 & 14 \\
& $(11.7)$ \\
\hline 3 & 26 \\
& $(21.7)$ \\
\hline 2 & 49 \\
& $(40.8)$ \\
\hline 1 & 27 \\
& $(22.5)$ \\
& 2 \\
Other $^{d}$ & $(1.7)$ \\
& 2 \\
No response & $(1.7)$
\end{tabular}

a Baseball, volleyball, tennis, aerobic, boxing, golf, Pilates, billiards, waking, cycling, jogging, jiu-jitsu, aquarobics, balling, or skating

\section{${ }^{\mathrm{b}}$ Alone}

c School, schoolyard, or indoors

dOccasionally or daily

The participants were asked to write up to three preferred exercises in order for the authors to understand their exercise preferences. The most preferred exercise activities were, in the following order: soccer (31 respondents), basketball (28 respondents), resistance exercise (27 respondents), badminton (23 respondents), and dance (20 respondents). Participants were also interested in taekwondo, dodgeball, jumping rope, swimming, and table tennis. Male participants preferred soccer, basketball, badminton, resistance exercise, and taekwondo, whereas female participants preferred dance, resistance exercise, badminton, basketball, and taekwondo. Sixty-five participants (54.2\%) preferred to exercise with friends, and $57(47.5 \%)$ had no preference for the exercise location. Moreover, 67 (55.8\%) participants chose to exercise for more than $30 \mathrm{~min}$, and $75(62.5 \%)$ participants chose to exercise between two and three times per week.

Table 4 presents the attitudes and intentions of childhood cancer survivors toward exercise. Sixty-seven participants $(55.9 \%)$ responded that exercising was very pleasant and $87(72.5 \%)$ responded that exercising was very beneficial. In addition, 77 (64.1\%) participants responded that exercising was fun, 77 
(64.1\%) responded that it was a very wise decision, 70 (58.3\%) responded that it was delightful, and 84 (70.0\%) responded that it was a very good activity. In addition, 76 (63.3\%) participants responded that they had the intention to exercise at least 3 times per week and 63 (52.5\%) reported that they had the intention to exercise regularly in the next month. 
Table 4

Attitudes and intention of childhood cancer survivors toward exercise

\begin{tabular}{|lll|}
\hline What do you think of exercising regularly? & & $\mathbf{n}(\%)$ \\
\hline It is very pleasant & Strongly agree & $38(31.7)$ \\
\hline Agree & $29(24.2)$ \\
\hline Neutral & $36(30.0)$ \\
\hline Disagree & $11(9.2)$ \\
\hline It is very beneficial & Strongly disagree & $6(5.0)$ \\
\hline Strongly agree & $40(33.3)$ \\
\hline Agree & $47(39.2)$ \\
\hline It is very good & Neutral & $23(19.2)$ \\
\hline Disagree & $9(7.5)$ \\
\hline Strongly disagree & $1(0.8)$ \\
\hline It is very fun & Strongly agree & $43(35.8)$ \\
\hline Agree & $34(28.3)$ \\
\hline Nery wise & Neutral & $28(23.3)$ \\
\hline Disagree & $11(9.2)$ \\
\hline Strongly disagree & $4(3.3)$ \\
\hline Strongly agree & $40(33.3)$ \\
\hline Agree & $37(30.8)$ \\
\hline Neutral & $32(26.7)$ \\
\hline Disagree & $9(7.5)$ \\
\hline Strongly disagree & $2(1.7)$ \\
\hline Strongly agree & $33(27.5)$ \\
\hline Agree & $37(30.8)$ \\
\hline Neutral & $37(30.8)$ \\
\hline Disagree & $8(6.7)$ \\
\hline Strongly disagree & $5(4.2)$ \\
\hline
\end{tabular}




\begin{tabular}{|lll|}
\hline What do you think of exercising regularly? & & $\mathbf{n}(\%)$ \\
\hline & Neutral & $27(22.5)$ \\
\cline { 2 - 3 } & Disagree & $6(5.0)$ \\
\cline { 2 - 3 } Intention to exercise of childhood cancer survivors & Strongly disagree & $3(2.5)$ \\
\hline I plan to exercise regularly in the next month & Strongly agree & $34(28.3)$ \\
\cline { 2 - 3 } & Agree & $42(35.0)$ \\
\cline { 2 - 3 } & Neutral & $29(24.2)$ \\
\cline { 2 - 3 } & Disagree & $9(7.5)$ \\
\cline { 2 - 3 } & Strongly disagree & $6(5.0)$ \\
I plan to exercise at least three times a week & Strongly agree & $28(23.3)$ \\
\cline { 2 - 3 } & Agree & $35(29.2)$ \\
\cline { 2 - 3 } & Neutral & $27(22.5)$ \\
\cline { 2 - 3 } & Disagree & $24(20.0)$ \\
\cline { 2 - 3 } & Strongly disagree & $6(5.0)$ \\
\hline
\end{tabular}

Figure 1 shows the exercise barriers in childhood cancer survivors. Of the 222 responses, the greatest perceived barriers to exercise were lack of time (39 respondents), poor health (36 respondents), and reluctance to sweat (34 respondents).

\section{Discussion}

This study explored the exercise participation patterns, exercise preferences, attitudes toward exercise, and perceived exercise barriers in childhood cancer survivors in childhood and adolescence. Only 16 participants (5\%) in the current study met the World Health Organization PA recommendation of 60 minutes of PA per day to gain health benefits for children and adolescents [23]. Although there are previously published reports of lower levels of PA participation in childhood cancer survivors, the low prevalence of only $5 \%$ of participants in the current study who met the PA guideline is of concern.

Furthermore, since most childhood cancer survivors are at school, it is also important to understand how much PA they are gaining from school PE. Although 81 (83.5\%) participants who attended school participated in PE classes at least once a week, it was unclear whether they fully participated in the activities during the class. In addition, only 35 (36.1\%) participants who attended school participated in sports clubs. Participation in school PE as well as sports clubs is an important resource for increasing PA among childhood cancer survivors. However, most childhood cancer survivors experience a long duration 
of cancer treatment and miss the opportunity to participate in age-appropriate exercise and PA, leading to a reduction in their physical literacy when they return to school [24]. Therefore, strategies are required to increase physical literacy for childhood cancer survivors, to increase participation in PE classes or exercise. In particular, pediatric oncologists, exercise therapists, education authorities, and social workers should endeavor to integrate individualized school plans and educate peers and teachers to improve health literacy to aid them in understanding the needs of childhood cancer survivors [25]. The most preferred activities among childhood cancer survivors differed from those of adult cancer survivors. The most popular activities among adult cancer survivors were walking and resistance exercises [26, 27], whereas the most popular exercise among childhood cancer survivors in our study included soccer, basketball, resistance exercise, badminton, and dance. In addition, most respondents preferred to exercise for > 30 min, twice a week, and $47.5 \%$ had no preference for the exercise location. These results provide information on the preferences of childhood cancer survivors, which need to be considered when developing and implementing exercise programs for this population group.

While more than $70 \%$ of participants responded that regular exercise was beneficial (72.5\%) and good (70\%), a smaller number of participants thought that regular exercise was pleasant (55.9\%) and delightful (58.3\%). Thus, most childhood cancer survivors realize that exercise is beneficial and good for them, but a significant portion of childhood cancer survivors think that exercise is not pleasant or delightful. This may be due to negative experiences while participating in exercise with peers at school or lack of physical ability to participate in sports.

The main barriers to exercise among the participants were lack of time, poor health, reluctance to sweat, lack of exercise skills, lack of exercise partners, and reluctance to be exposed to the sun. Compared to adult cancer survivors, childhood cancer survivors felt that they did not have enough time to exercise because of the burden of studies and schoolwork. In addition, the childhood cancer survivors included in this study reported that they had health problems including fatigue, adverse effects, and acquired disabilities after cancer treatment.

Since childhood cancer survivors could gain health benefits, including an improved QOL, motivating them to participate in more PA is essential. To increase their PA participation, it is important to understand exercise preferences, attitudes toward exercise, and exercise barriers. Exercise programs for childhood cancer survivors should be tailored according to their personal preferences and barriers to increase compliance. Furthermore, they should aim to improve physical literacy while also being fun and pleasant in order to increase adherence and compliance.

This study has several limitations. The sample size was small, and the study was conducted at a single center. Furthermore, as this was a cross-sectional study, it was difficult to identify causal effects. Thus, further studies including multiple centers and larger sample sizes are needed to evaluate exercise preferences and barriers to exercise among childhood cancer survivors. Despite these limitations, this study is the first step in evaluating the PA of childhood cancer survivors. None of the evaluation tools reported in the PA, exercise, and pediatric oncology studies assess the physical literacy of childhood 
cancer survivors [28]. In addition, the participants of the current study had recently undergone treatment and were still in childhood or adolescence. This study may provide basic data on the physical literacy of childhood cancer survivors.

In conclusion, childhood cancer survivors did not meet the PA recommendations for gaining health benefits for children and adolescents. As mentioned above, PA tends to improve physical fitness, psychological health, and QOL while decreasing fatigue and depression. This study demonstrated the exercise preferences and barriers to exercise among childhood cancer survivors. Exercise programs that integrate the preferences of this group, such as exercise type, frequency, time, and barriers, are required.

\section{Declarations}

Funding This research project was funded by the Korean Foundation for Cancer Research (KFCR-2017001).

Conflicts of interest/Competing interests All authors declare that they have no conflict of interest.

Available of data and material Data is available from the corresponding author on reasonable request.

\section{Code availability N/A}

Authors' contributions All authors contributed to the study conception and design. Material preparation, data collection, and analysis were performed by Ji Young Kim, Samuel Yoo, Su Jin Yeon, and Ji Hee Min. Participant recruitment was performed by Jung Woo Han and Chuhl Joo Lyu. The first draft of the manuscript was written by Ji Young Kim and Dong-il Kim, Ji Won Lee, Chuhl Joo Lyu, and Justin Y. Jeon commented on previous versions of the manuscript. All authors read and approved the final manuscript.

Ethics approval This study was approved by the ethics review committee of the Yonsei University College of Medicine (approval no. 4-2017-0065).

Consent to participate All participants provided informed consent and assent prior to enrollment.

Consent for publication All participants provided consent for publication during the informed consent process.

Acknowledgment: This work was supported by the Korean Foundation for Cancer Research (KFCR-2017001).

\section{References}

1. Lähteenmäki, P. M., Huostila, J., Hinkka, S., Salmi, T. T. (2002). Childhood cancer patients at school. Eur J Cancer, 38(9),1227-1240. 
2. Oeffinger, K. C., Mertens, A. C., Sklar, C. A., Kawashima, T., Hudson, M. M., Meadows, A. T., et al. (2006). Chronic health conditions in adult survivors of childhood cancer. N Engl J Med, 355(15), 1572-1582.

3. Scott, J. M., Li, N., Liu, Q., Yasui, Y., Leisenring, W., Nathan, P. C., et al. (2018). Association of exercise with mortality in adult survivors of childhood cancer. JAMA oncology, 4(10), 1352-1358.

4. Ness, K. K., Plana, J. C., Joshi, V. M., Luepker, R. V., Durand, J. B., Green, D. M., et al. (2020). Exercise intolerance, mortality, and organ system impairment in adult survivors of childhood cancer. $\mathrm{J}$ Clin Oncol, 38(1), 29-42.

5. Alvarez, J. A., Scully, R. E., Miller, T. L., Armstrong, F. D., Constine, L. S., Friedman, D. L., et al. (2007). Long-term effects of treatments for childhood cancers. Curr Opin Pediatr, 19(1), 23-31.

6. Diller, L., Chow, E. J., Gurney, J. G., Hudson, M. M., Kadin-Lottick, N. S., Kawashima, T. I., et al. (2009). Chronic disease in the Childhood Cancer Survivor Study cohort: a review of published findings. J Clin Oncol, 27(14), 2339.

7. Götte, M., Taraks, S., Boos, J. (2014). Sports in pediatric oncology: the role (s) of physical activity for children with cancer. J Pediatr Hematol Oncol, 36(2), 85-90.

8. Paxton, R. J., Jones, L. W., Rosoff, P. M., Bonner, M., Ater, J. L., Demark-Wahnefried, W. (2010). Associations between leisure-time physical activity and health-related quality of life among adolescent and adult survivors of childhood cancers. Psychooncology, 19(9), 997-1003.

9. Stolley, M. R., Restrepo, J., Sharp, L. K. (2010). Diet and physical activity in childhood cancer survivors: a review of the literature. Ann Behav Med, 39(3), 232-249.

10. Winter, C., Müller, C., Hoffmann, C., Boos, J., Rosenbaum, D. (2010). Physical activity and childhood cancer. Pediatr Blood Cancer, 54(4), 501-510.

11. Hocking, M. C., Schwartz, L. A., Hobbie, W. L., DeRosa, B. W., Ittenbach, R. F., Mao, J. J., et al. (2013). Prospectively examining physical activity in young adult survivors of childhood cancer and healthy controls. Pediatr Blood Cancer, 60(2), 309-315.

12. Demark-Wahnefried, W., Werner, C., Clipp, E. C., Guill, A. B., Bonner, M., Jones, L. W., et al. (2005) Survivors of childhood cancer and their guardians: current health behaviors and receptivity to health promotion programs. Cancer, 103(10), 2171-2180.

13. Keats, M. R., Courneya, K. S., Danielsen, S., Whitsett, S. F. (1999). Leisure-time physical activity and psychosocial well-being in adolescents after cancer diagnosis. Journal of Pediatric Oncology Nursing, 16(4), 180-188.

14. Keats, M. R., Culos-Reed, S. N., Courneya, K. S., McBride, M. (2006). An examination of physical activity behaviors in a sample of adolescent cancer survivors. Journal of pediatric oncology nursing, 23(3), 135-142.

15. Antwi, G. O., Jayawardene, W., Lohrmann, D. K., Mueller, E. L. (2019). Physical activity and fitness among pediatric cancer survivors: a meta-analysis of observational studies. Support Care Cancer, 27(9), 3183-3194. 
16. Schindera, C., Weiss, A., Hagenbuch, N., Otth, M., Diesch, T., von der Weid, N., et al. (2020). Physical activity and screen time in children who survived cancer: A report from the Swiss Childhood Cancer Survivor Study. Pediatr Blood Cancer, 67(2), e28046.

17. Ness, K. K., Leisenring, W. M., Huang, S., Hudson, M. M., Gurney, J. G., Whelan, K., et al. (2009). Predictors of inactive lifestyle among adult survivors of childhood cancer: a report from the Childhood Cancer Survivor Study. Cancer, 115(9), 1984-1994.

18. Florin, T. A., Fryer, G. E., Miyoshi, T., Weitzman, M., Mertens, A. C., Hudson, M. M., et al. (2007). Physical inactivity in adult survivors of childhood acute lymphoblastic leukemia: a report from the childhood cancer survivor study. Cancer Epidemiol Biomarkers Prev, 16(7), 1356-1363.

19. Chung, O. J., Li, H. C. W., Chiu, S. Y., Ho, K. Y. E., Lopez, V. (2014). The impact of cancer and its treatment on physical activity levels and behavior in Hong Kong Chinese childhood cancer survivors. Cancer nurs, 37(3), E43-E51.

20. Chung, J. Y., Lee, D. H., Park, J. H., Lee, M. K., Kang, D. W., Min, J., et al. (2013). Patterns of physical activity participation across the cancer trajectory in colorectal cancer survivors. Support Care Cancer, 21(6), 1605-1612.

21. Godin, G., Jobin, J., \& Bouillon, J. (1986). Assessment of leisure time exercise behavior by self-report: a concurrent validity study. Can J Public Health, 77(5), 359-362.

22. SO, WY. (2012). Association between physical activity and academic performance in Korean adolescent students. BMC Public Health, 12(1), 1-7.

23. World Health Organization (2003). Annual global move for health initiative: a concept paper.

24. Chamorro Viña, C., Guilcher, G. M., Schulte, F., De Vries, A., Schwanke, J., \& Culos-Reed, S. N. (2017). Description of a community-based exercise program for children with cancer: a sustainable, safe, and feasible model. Rehabil Oncol, 35(1), 24-37.

25. Lee, J. A., Lee, J. M., Park, H. J., Park, M., Park, B. K., Ju, H. Y., et al. (2020). Korean parents' perceptions of the challenges and needs on school re-entry during or after childhood and adolescent cancer: a multi-institutional survey by Korean Society of Pediatric Hematology and Oncology. Clin Exp Pediatr, 63(4), 141.

26. Rogers, L. Q., Courneya, K. S., Shah, P., Dunnington, G., Hopkins-Price, P. (2007). Exercise stage of change, barriers, expectations, values and preferences among breast cancer patients during treatment: a pilot study. Eur J Cancer Care, 16(1), 55-66.

27. Rogers, L. Q., Malone, J., Rao, K., Courneya, K. S., Fogleman, A., Tippey, A., et al. (2009). Exercise preferences among patients with head and neck cancer: prevalence and associations with quality of life, symptom severity, depression, and rural residence. Head Neck, 31(8), 994-1005.

28. Shank, J., Chamorro-Viña, C., Guilcher, G. M., Langelier, D. M., Schulte, F., Culos-Reed, S. N. (2020). Evaluation Tools for Physical Activity Programs for Childhood Cancer: A Scoping Review. J Pediatr Oncol Nurs, 37(3), 163-179. 


\section{Figures}

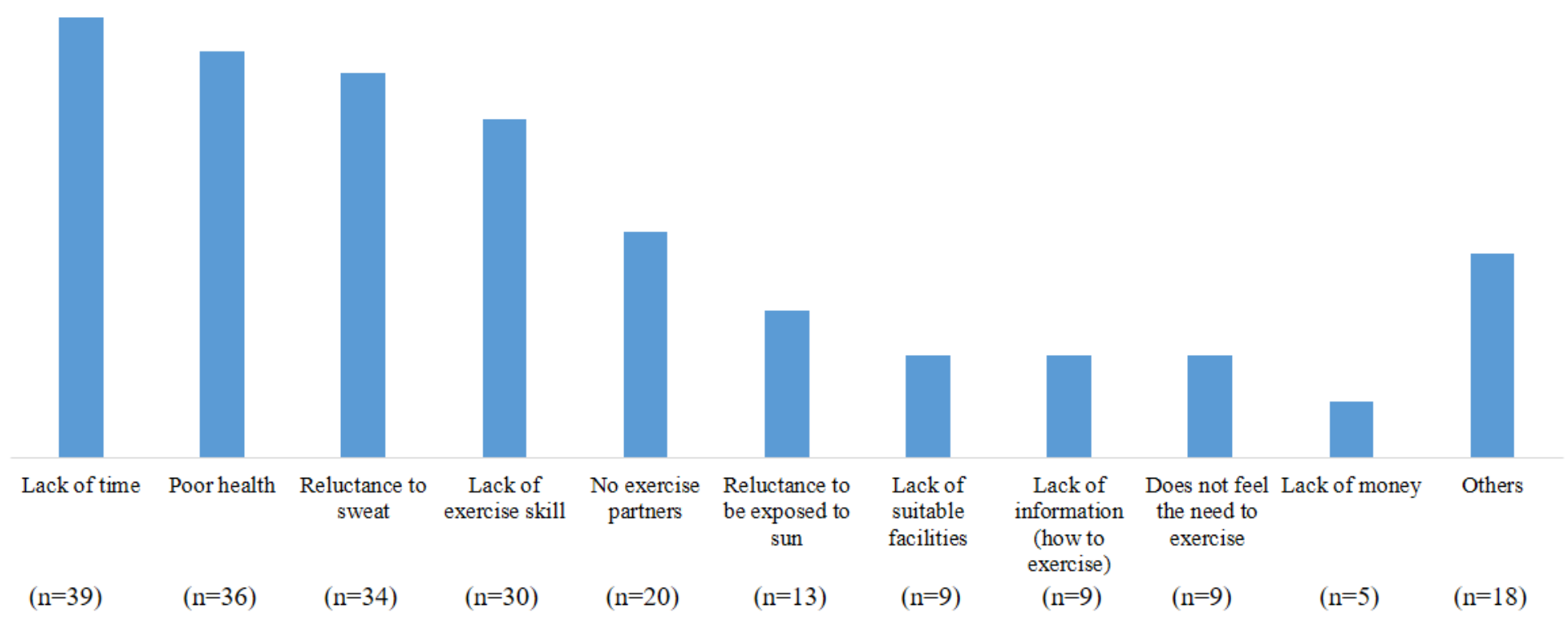

Other; None, not feeling well, bothersome, bad weather

\section{Figure 1}

Exercise barriers of childhood cancer survivors (multiple choices) 